\title{
PERANCANGAN MEDIA KATALOG SEBAGAI PENUNJANG INFORMASI DAN PROMOSI PADA CV.ZERO STORE
}

\author{
Dewi Immaniar Desrianti ${ }^{1}$ \\ Anita B Wandanaya ${ }^{2}$ \\ Asih Sumaryani ${ }^{3}$ \\ e-mail: dewi.immaniar@raharja.info,anita@raharja.info,asih_dpooh@rocketmail.com
}

Diterima : 11 Desember 2013 / Disetujui : 20 Desember 2013

\begin{abstract}
With the development of computer technology, especially in the field of multimedia enabling competition in the highly competitive retail world. At the present time due to intense competition in the business world, the service and quality of goods is not enough to be able to increase revenue and attract customers who are loyal and inevitably this makes employers think hard to find a way to survive and stable in the business. One way is to use visual communication media can indirectly communicate the expected value of its effectiveness in product marketing programs . CV.Zero Store is a company located in Villa Mutiara Pluit Tangerang which sells a variety of products and a jersey type shirt screen printing. The problems that exist in the company does not have a means of supporting media promotion of effective programs, this company is already using a media campaign to promote its products as it is used today is the brochures, banners, promotions with clients directly keklien and perceived inadequate for future promotion. Therefore, it takes promosiyang other means such as the media in the desired catalog marketing targets that have been programmed. For media catalog is a masterpiece of design that is packaged in the form of a booklet which is a medium that can be made in the company's assets that can be used to improve an image or the image of the company to establish cooperation relations with companies, institutions and other relevant agencies. Besides the new design is expected to add variants of the media campaign so as to form the image or the image of the company as desired. Therefore dituangkanlah such a design in an article entitled "Designing Catalog For Supporting Information Media and Promotions at CV Zero.Store “
\end{abstract}

1. Dosen Jurusan Teknik Informatika, STMIK Raharja

Jl. Jend Sudirman No. 40 Modern Cikokol-Tangerang Telp. 5529692

2. Dosen Jurusan Teknik Informatika, STMIK Raharja

Jl. Jend Sudirman No. 40 Modern Cikokol-Tangerang Telp. 5529692

3. Mahasiswa Jurusan Teknik Informatika, STMIK Raharja

Jl. Jend Sudirman No. 40 Modern Cikokol-Tangerang Telp. 5529692 
Keywords: Information, Promotion, Profile, Image Enhancement, catalog

\begin{abstract}
ABSTRAKSI
Dengan adanya perkembangan teknologi dibidang komputer khususnya multimedia memungkinkan persaingan dalam dunia retail sangat bersaing. Pada masa sekarang ini seiring dengan ketatnya persaingan dalam dunia bisnis, pelayanan dan kualitas barang tidaklah cukup untuk bisa meningkatkan pendapatan dan menjaring konsumen yang loyal dan mau tidak mau hal ini membuat para pemilik perusahaan berpikir keras untuk menemukan cara agar bisa bertahan dan stabil dalam bisnisnya. Salah satu caranya adalah dengan menggunakan media komunikasi visual yang secara tidak langsung dapat diharapkan nilai efektifitasnya dalam mengkomunikasikan program-program pemasaran produk. CV.Zero Store merupakan perusahaan yang terletak di Villa Mutiara Pluit Tangerang yang menjual produk bermacam-macam jenis jersey dan kaos sablon. Permasalahan yang ada pada perusahaan tersebut belum mempunyai media-media sarana penunjang program promosi yang efektif, perusahaan ini memang telah menggunakan media promosi untuk mempromosikan produk-produknya seperti yang dipakai saat ini adalah brosur, spanduk, promosi dengan klien secara langsung keklien dan dirasakan kurang memadai untuk promosi kedepannya. Oleh sebab itu, dibutuhkan sarana-sarana promosiyang lainnya seperti media Katalog yang diinginkan dalam target pemasaran yang telah diprogramkan. Untuk media Katalog yaitu suatu karya desain yang dikemas berupa booklet yang merupakan sebagai media yang dapat di jadikan asset perusahaan yang dapat digunakan untuk meningkatkan suatu image atau citra dari perusahaan untuk menjalin kerja sama dengan relasi perusahaan, lembaga dan instansi terkait lainnya. Selain itu perancangan yang baru ini diharapkan dapat menambah variant dari media promosi sehingga dapat membentuk image atau citra perusahaan sesuai dengan yang diinginkan. Maka dari itu dituangkanlah sebuah desain tersebut dalam sebuah artikel yang berjudul "Perancangan Media Katalog Sebagai Penunjang Informasi dan Promosi Pada CV Zero.Store”.
\end{abstract}

Kata Kunci: Informasi, Promosi, Profil, Peningkatan Image, Katalog

\title{
I. PENDAHULUAN
}

Pada dasarnya berkembangnya media informasi saat ini dan bidang komputerisasi khususnya multimedia kian hari semakin meningkat dan telah mendorong terjadinya arus globalisasi, dimana banyak pihak-pihak yang terlibat, baik yang berhubungan langsung dalam proses penyampaian maupun penerimaan informasi tersebut. Model dan sistem penyampaian informasi ini akan menentukan, apakah proses tersebut berjalan dengan baik dan efektif. Pemberian informasi merupakan suatu usaha yang dibutuhkan perusahaan karena dengan adanya informasi 
perusahaan, maka perusahaan akan mendapatkan keuntungan yaitu dikenal secara umum.

CV. Zero Store adalah sebuah perusahaan yang bergerak dibidang pakaian sport khususnya jersey yang beralamat di villa mutiara pluit Tangerang-Banten 15131. Saat ini CV.Zero Store menggunakan media promosi dan informasi dalam bentuk media cetak saja yaitu masih berupa spanduk, brosur, dan melakukan promosi keklien secara lisan, melakukan pemasaran dengan memperlihatkan foto-foto port folio dan fasilitas yang belum dikemas dalam bentuk katalog yang sudah rapi dan terorganisasi dengan baik.

Dalam mengembangkan usahanya saat ini CV.Zero Store sangat membutuhkan media informasi dan promosi yang mampu mengemas seluruh fasilitas yang dimiliki perusahaan dalam menjalani relasi atau kerja sama baik dengan klien perseorangan,klien perusahaan, instansi ataupun lembaga terkait.

Dari hasil analisa kebutuhan yang dilakukan penulis terhadap CV. Zero Store perusahaan tersebut membutuhkan katalog dalam bentuk booklet untuk memperkenalkan seluruh kapasitas perusahaan dan diharapkan melalui perancangan katalog ini dapat meningkatkan omset perusahaan.

Tujuan dari Penelitian ini adalah dapat menciptakan media katalog yang menarik mengenai profil dan aktifitas perusahaan,sebagai media informasi yang lebih efektif tentang perusahaan,sebagai media promosi agar mendapatkan kepercayaan dari calon konsumen dan perusahaan yang ingin bekerja sama dengan CV.Zero Store dan sebagai penunjang promosi dan informasi yang sesuai dengan image CV.Zero Store.

\section{KAJIAN LITERATUR}

Sebelumnya,terdapat banyak penelitian yang dilakukan mengenai perancangan media katalog. Beberapa Kajian Literatur adalah sebagai berikut :

1 Penelitian ini dilakukan oleh Gunanto Setiawan dari STMIK AMIKOM Yogyakarta pada tahun 2010 yang berjudul “ Analisis Dan Perancangan Aplikasi Mobile Katalog Buku Dengan Teknologi J2ME Pada Penerbit Dan Percetakan AR-Ruzz Media Yogyakrta.” Penelitian ini membahas mengenai pembuatan sebuah aplikasi mobile katalog buku yang dapat diakses melalui handphone.

2. Penelitian ini dilakukan oleh Salis Tusfia dari STMIKAMIKOM Yogyakarta pada tahun 2010 yang berjudul “ Pembuatan Katalog Digital Museum 
Anak Kolong Tangga di Taman Budaya Yogyakarta dengan Menggunakan Macromedia Flash $M X$ ” Penelitian ini menjelaskan tujuan utama membuat katalog digital adalah untuk membantu penyampain informasi.

3. Penelitian ini dilakukan oleh Putra Uji Deva Satrio dari Universitas Negeri Malang tahun 2011 yang berjudul "Perancangan Media Katalog Wisata Kota Surabaya Sebagai Media Informasi Massa "Penelitian ini menjelaskan tujuan utama membuat media katalog adalah untuk mempromosikan tempattempat wisata di kota Surabaya memberikan kemudahan informasi kepada masyarakat umum.

Dari tiga literatur diatas dapat disimpulkan bahwa media katalog adalah media yang efektif dalam menyampaikan informasi dan promosi. Literature diatas banyak menjelaskan mengenai katalog sebagai pengembang informasi dalam studi kasus bidang wisata dan didang publikasi sedangkan dalam bisnis komersial dan retail belum banyak dibahas. Mengenai sisi desainnya tiga literature diatas kurang menjabarkan sisi desainnya. Sedangkan artikel ini akan lebih banyak membahas mengenai sisi desainnya.

\section{METODE PENELITIAN}

Pelaksanaan penelitan yang dilakukan melakukan beberapa metode diantaranya:

1. Metode Analisa Permasalahan

Adalah sebuah metode agar kita mampu menentukan akar masalah dari berbagai masalah yang terjadi dalam sebuah lembaga atau realita untuk melakukan analisa masalah dengan mengunakan pendekatan ekspektasi dan pendekatan realita.

2. Metode Pengumpulan Data

a. Metode Observasi

Metode yang dilakukan dengan cara pengumpulan data dan mengadakan pengamatan langsung terhadap suatu obyek dalam suatu periode tertentu dan mengadakan pencatatan secara sistematis tentang hal-hal tertentu yang diamati.

b. Metode Interview 
Metode pengumpulan data dengan jalan tanya jawab lisan secara sepihak yang dikerjakan secara sistematis dan berlandaskan pada tujuan penelitian. Tehnik wawancara yang penulis gunakan adalah wawancara bebas terpimpin dimana pewawancara menyajikan daftar pertanyaan, akan tetapi cara bagaimana pewawancara menyajikan diserahkan kepada kebijaksanaan pewawancara.

\section{c. Studi Pustaka}

Selain melakukan observasi dengan wawancara penulis juga melakukan pengumpulan data dengan cara Studi Pustaka, dalam hal ini penulisberusaha melengkapi data-data yang diperoleh dengan cara membacabuku-buku atau literatur-literatur yang ada. Penulis juga melakukan Studi Pustaka melalui sumber-sumber yang berhubungan dengan judul yang diajukan untuk membantu dalam penganalisaan dan sebagai acuan yang dilakukan penulis.

\section{Metode Analisa Perancangan Konsep Desain}

Perancangan media katalog sebagai media yang digunakan untuk menunjang media promosi dan informasi dirancang berdasarkan pengumpulsn dats dan analisa terhadap media yang telah digunakan sebelumnya sebsgsi promosi selanjutnya dirancang proses pembuatan media desain mulai dari Layout Kasar hingga Final Artwork.

\section{PEMBAHASAN}

\section{Posisi Pasar (Market Positioning)}

CV.Zero Store yang terletak di perumahan Villa Mutiara Pluit Tangerang merupakan salah satu perusahaan yang sudah berkembang dengan cukup pesat. Hal ini dapat dilihat dari pelanggan yang tidak hanya berada dilingkungan perumahan tetapi juga yang berada diluar lingkungan perumahan Villa Mutiara. CV.Zero Store memiliki banyak sekali pelanggan tetap.

Pelanggan Perusahaan melingkupi semua kalangan. CV.Zero Store memiliki citra atau image yang baik, hal ini dibuktikan dengan adanya kepercayaan dari konsumen. market position CV.Zero Store berada di Kota Bumi Tangerang.

2. Kondisi Pesaing

Berikut adalah tabel pesaing yang merupakan kompetitor CV.Zero Store Tangerang yang berada di wilayah sekitar Kota Tangerang : 
Tabel 1.daftar pesaing

\begin{tabular}{|c|c|c|}
\hline Nama Pesaing & Kelebihan & Kekurangan \\
\hline Toko Sun Sport & $\begin{array}{l}\text { Harga produk } \\
\text { terjangkau } \\
\text { dan kualitas } \\
\text { produk cukup } \\
\text { baik Lokasi } \\
\text { tepat } \\
\text { dipinggir } \\
\text { jalan }\end{array}$ & $\begin{array}{l}\text { Kegiatan } \\
\text { Promosinya } \\
\text { masih kurang }\end{array}$ \\
\hline Valentin Sport & $\begin{array}{l}\text { Kualitas } \\
\text { produk baik, } \\
\text { kadang } \\
\text { barang lebih } \\
\text { lengkap }\end{array}$ & Harga mahal \\
\hline
\end{tabular}

\section{Potensial Market}

Potensi pasar dari perusahaan ini berada diwilayah Tangerang dan sekitarnya, dengan pangsa pasar yang cukup signifikan. Target penjualan produk pada tahuntahun berikutnya diperkirakan akan meningkat, karena pertumbuhan ekonomi dan yang pesat pada saat ini dan semakin banyaknya perusahaan-perusahaan yang baru berdiri.

4. Market Segmentation

a. Geografi: Kota Tangerang dan sekitarnya.

b. Demografi :

1. Jenis kelamin : : Pria dan Wanita.

2. Golongan ekonomi : Umum (mencakup semua kelas ekonomi)

3. Sasaran : Konsumen individu atau perusahaan

c. Psikografi : Bagi konsumen khususnya yang memerlukan produk jersey atau sablon.

5. Software yang digunakan

Dalam Konsep media informasi dan promosi software yang digunakan adalah Adobe Photoshop Cs2 dan Illustrator CS2. 
Definisi Software yang digunakan :

a. Adobe Photoshop Cs2 adalah suatu perngkat lunak canggih yang dapat kita gunakan membuat,menyunting dan memanipulasi tampilan termasuk mengoreksi dan member efek tampilan atas sebuah gambar atau photo hasil dari program ini merupakan sebuah gambar/image didalam computer grafis terbagi menjadi 2kelompok yaitu gambar Bitmap dan gambar Vektor

b. Adobe Illustrator Cs2 adalah program grafis berbasis vector yang paling tanggunh dan popular karena faslitas-fasilitas yang ada didalamnya dapat digunakan untuk membentuk objek secara tiga dimensi sehingga hasil yang diperoleh menyerupai objek yang sebenarnya.

\section{Tujuan Kreatif}

Saat ini banyak perusahaan yang bergerak dibidang yang sama dengan CV.Zero Store sehingga perusahaan mengalami tahap kompetisi dan juga tahap dalam menjalin kerja sama dengan perusahaan lain. Oleh karena itu untuk mempertahankan konsumen yang telah ada dan juga bertujuan untuk menjaring calon konsumen yang baru di butuhkan sebuah media yang dapat mencapai tujuan tersebut. Dengan dasar hal tersebut maka tujuan utama dari perancangan majalah perusahaan ini adalah :

a. Meyakinkan khalayak sasaran khususnya pelaku bisnis yang ingin melakukan kerjasama dengan perusahaan.

b. Menciptakan image atau citra yang baik bagi perusahaan

c. Menginformasikan kuantitas dan kualitas akan produk-produk yang ada.

\section{Strategi Kreatif}

Dalam perencanaan sarana media penunjang promosi dirancang sebuah mdia promosi Katalog, Tujuan program promosi dapat tercapai harus bisa menyampaikan informasi yang tepat dan menarik kepada konsumen selain dari media yang dirancang harus bisa efektif dalam penggunannya.Selaian media tersebut berisi tentang seluruh profil yang ada diperusahaan juga informasi prosuk,meda tersebut sekaligus sebagai sarana penunjang promosi dan dapat meningkatkan citra atau image CV.Zero Store.

\section{Penulisan Naskah}

Agar Penyampaian pesan bisa tepat sasaran, maka pesan media dibuat secara terurut dengan alur yang benar,yaitu :

1) Judul (headline) : KATALOG CV.ZERO STORE, Logo CV.Zero Store 
2) Sub-sub halaman berikutnya disampaikan sesuai dengan urutan isi company profile : Daftar isi,profil perusahaan, visi dan misi perusahaan , informasi produk,artikel mengenai sport dll)

Dalam pembuatan media promosi Katalog tersebut terlihat menarik dan tidak terlihat kaku tampilan grafisnya,maka rancangan media tersebut mengikuti kaidah-kaidah sebagai berikut :

a. Totalitas warna yang dipilih diantaranya

1) Warna Biru : :Melambangkan kebenaran, keteguhan, ketenangan, kesejukan, kesetiaan dan kemurahan hati.

2) Warna Putih : Respon psikologisnya yaitu, kesucian, kebersihan, ketepatan dan steril.

3) Warna Hitam :Respon psikologisnya yaitu, kekaburan, kerahasian dan sesuatu yang tidak diketahui.

4) Warna Abu-abu : Ketaatan, rendah hati, kesholihan, modern.

5) Warna Coklat : Memberikan kesan hangat, nyaman dan aman

6) Warna Hijau : : Pertumbuhan, kesuburan, keremajaan, keyakinan, pengharapan, kesanggupan, kehidupan, penelitian.

7) Warna Oranye : Kemajuan, semangat, perkembangan, Energi.

b. Jenis huruf yang relevan adalah :

Jenis huruf yang dipakai dalam perancangan diantaranya jenis huruf yang karakternya sesuai dengan karakter huruf yang selama ini dipergunakan oleh CV.Zero Store yang bersangkutan, yaitu : Arial, , Times New Roman,,DaunPenh,Pristina,Arial,BIRTH OF A HERO, Wide latin,Verdana,FRANKINGOTHICDEMI,Algerian,PlagueDeath,Deddy Ohip, Matira MT Script Capitals,Stencil,Brownwood NF,Edo,Tempas San ITC

c. Tata letak atau layout yang digunakan adalah :

Tata letak disesuaikan dengan media elemen-elemen yang terdapat di rancangan media katalog dengan menata atau menyatukan unsur-unsur mulai dari teks,gambar dan warna agar menjadi media katalog yang komunikatif dan dapat menarik perhatian relasi.

d. Gaya penampilan grafis

Gaya tampilan visual secara grafis ditampilkan minimalis tapi terkesan modern yang komunikatif, dimaksudkan agar audience dapat lebih mudah mengetahui pesan media yang disampaikan. 


\section{Manfaat Media Katalog}

Perancangan media promosi dan informasi yang ada selama ini masih diterapkan dalam bentuk media cetak dan juga promosi secara langsung keklien sehingga promosi yang dilakukan masih kurang maksimal. Disamping masalah promosi juga untuk menjalin kerja sama dengan klien atau perusahaan-perusahaan dibutuhkan rancangan yang mampu mengemas seluruh fasilitas yang dimiliki perusahaan dan informasi produk. Dengan Perancangan media katalog yang digunakan sebagai media promosi dapat menjadi penunjang promosi dan informasi yang sesuai dengan image atau citra perusahaan. Secara garis besar dapat kita lihat pada gambar berikut:

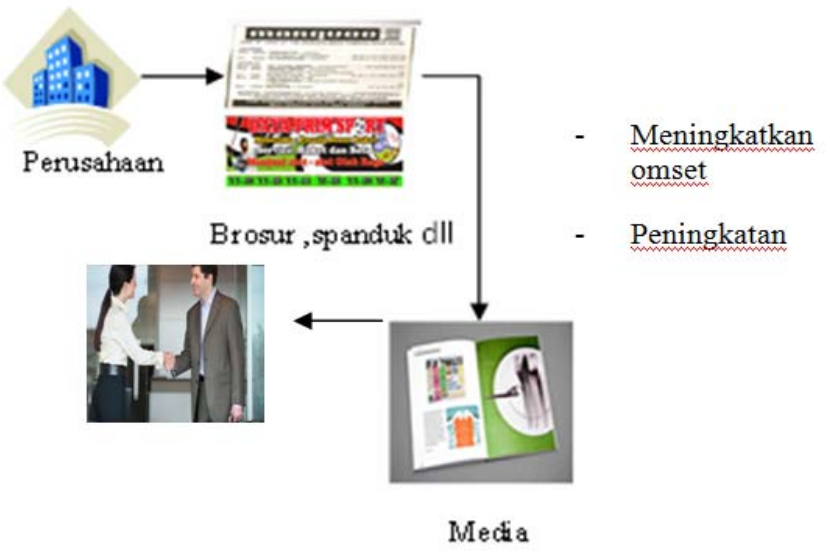

Gambar1. Manfaat Media Katalog

Dari penjelasan gambar diatas dapat disimpulkan bahwa menggunakan media katalog lebih mudah dalam melakukan media informasi dan promosi dan melakukan kerja sama kepada perusahaan atau klien,disamping itu dapat meningkatkan omset,peningkatan image dan kepercayaan.

\section{Perancangan Desain}

Tampilan Perancangan media katalog yang digunakan untuk media promosi perusahaan yang terdiri dari Layout Kasar,Layout Komprehensif,dan Final Art Work.

1. Layout Kasar.

Layout Kasar adalah Penerapan elemen-elemen desain media yang nantinya 
akan dipergunakan dalam perancangan media katalog yang disertai acuan standarisasi pada desain yang akan dibuat,umumnya dibuat dengan tampilan hitam putih,dibuat dengan coretan atau sketsa dengan menggunakan pensil gambar.Layout Kasar diperlukan sebagai panduan pada saat diproses desain dengan menggunakan aplikasi computer. Berikut Layout kasar yang dibagi menjadi 2 :

a. Layout kasar Cover Depan dan Belakang Katalog CV.Zero Store

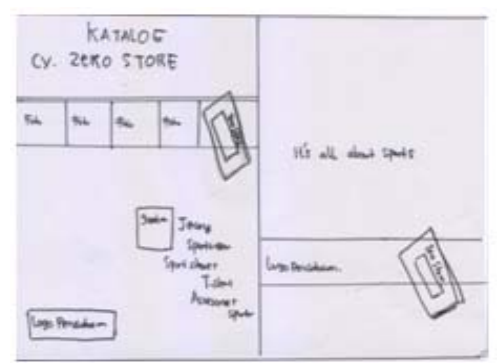

Gambar 2.Layout Kasar Cover Depan dan Belakang CV.Zero Store

b. Layout Kasar hal 1-21
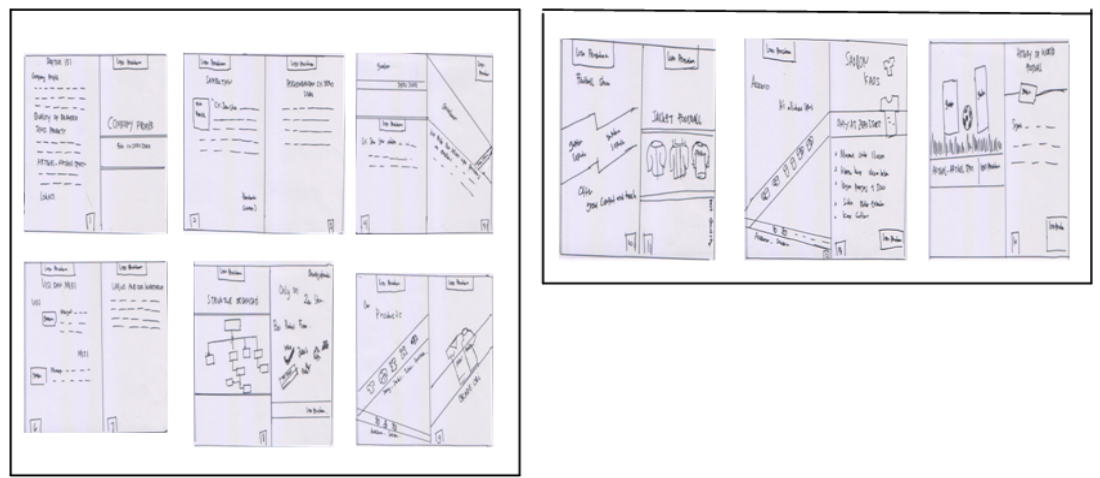

Gambar 3. Layout Kasar hal 1-21

\section{Layout Komprehensif}

Layout Komprehensif adalah Proses desain yang sudah memasuki tahap komputerisasi san pewarnaan,namun tahap ini belum selesai seluruhnya,karena masih harus mengalami proses revisi. Berikut Layout Komprehensif yang dibagi 2 :

a. Layout Komprehensif Cover Depan dan Belakang Katalog 


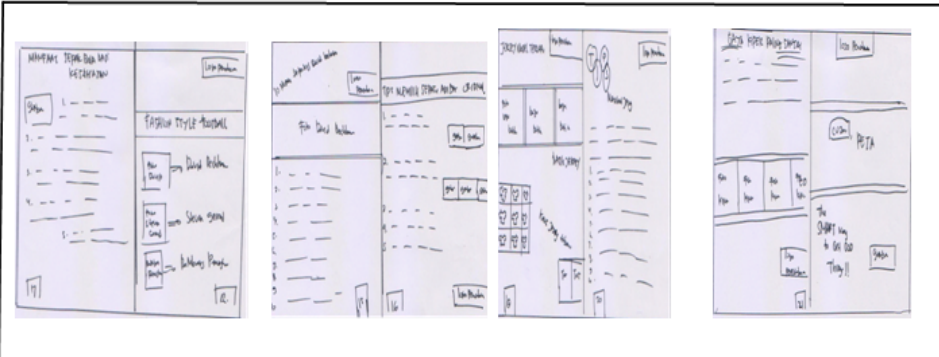

Gambar 4. Layout Komprehensif Cover Depan dan Belakang Katalog

b. Layout Komprehensif hal 1-21

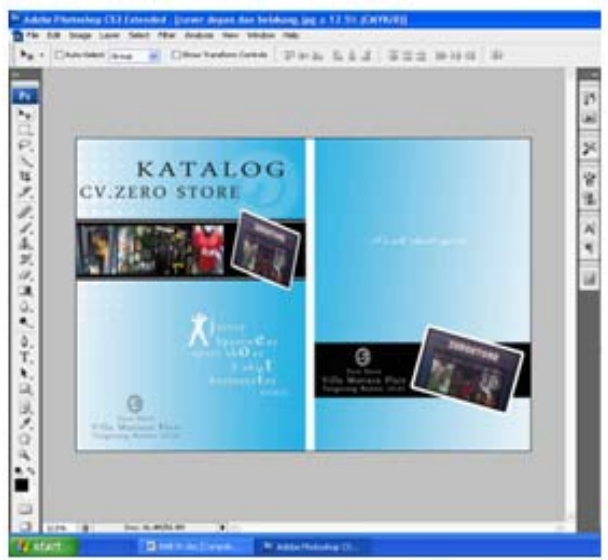

Gambar 5. Layout Komprehensif hal 1-21

\section{Final Art Work}

Final Art Work adalah hasil akhir dari layout komprehensif yang telah diperbaiki.dimana tahap ini merupakan hasil akhir atau finishing yang kemudian dapat digunakan untuk acuan saat proses produksi.

\section{a. Final Art Work Depan dan Belakang}

Final Art Work untuk cover depan terdapat logo perusahaan,informasi produk dan foto perusahaan yang merupakan image atau citra dari perusahaan tersebut dengan menggunakan ukuran 21x29 cm dengan Cover kertas Art Carton dan Isi kertas Art Paper. 


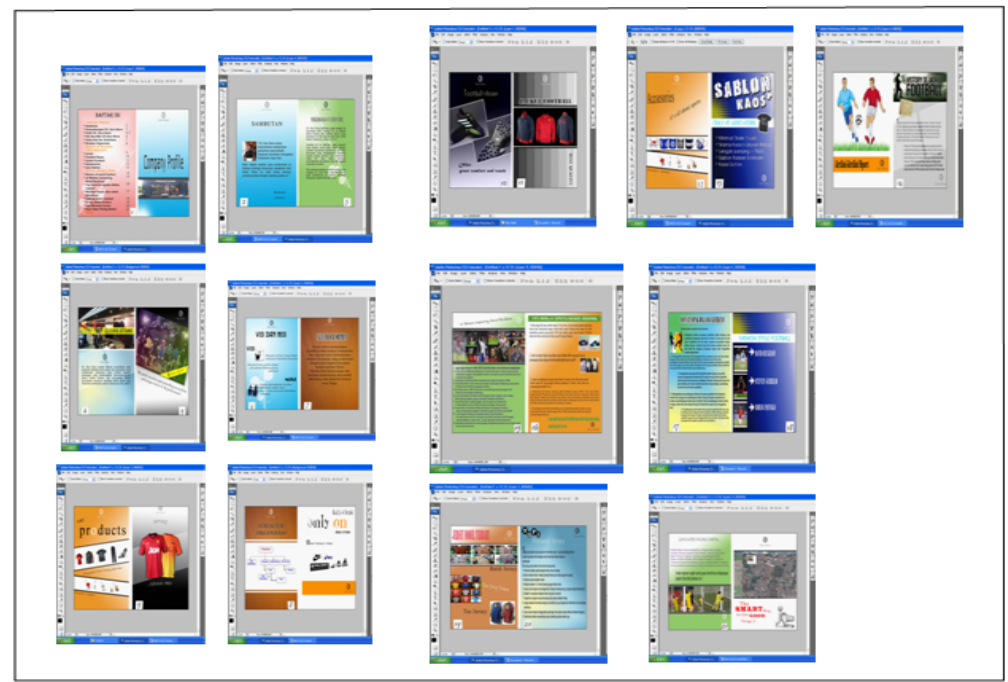

\section{Gambar 6.Final Art Work Cover Depan dan Belakang}

\section{b. Final Art Work Daftar isi dan Company Profile}

Pada Final Art Work ini terdapat daftar isi yang merupakan urutan dari katalog yang dibuat dan terdapat company profile.
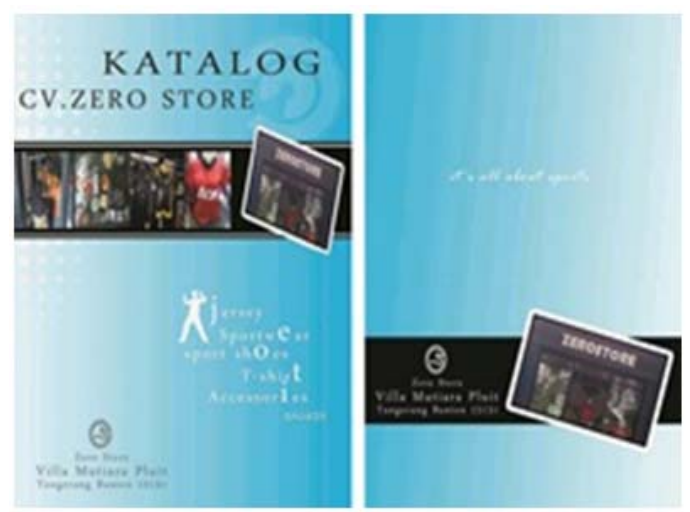

Gambar 7. Final Art Work Daftar isi dan Company Profile.

c. Final Art Work Sambutan dan perkembangan Perusahaan serta profil perusahaan.

Final Art Work ini menjelaskan tentang Sambutan dan Perkembangan Perusahaan. Final Art Work ini menjelaskan tentang Profil Perusahaan. 


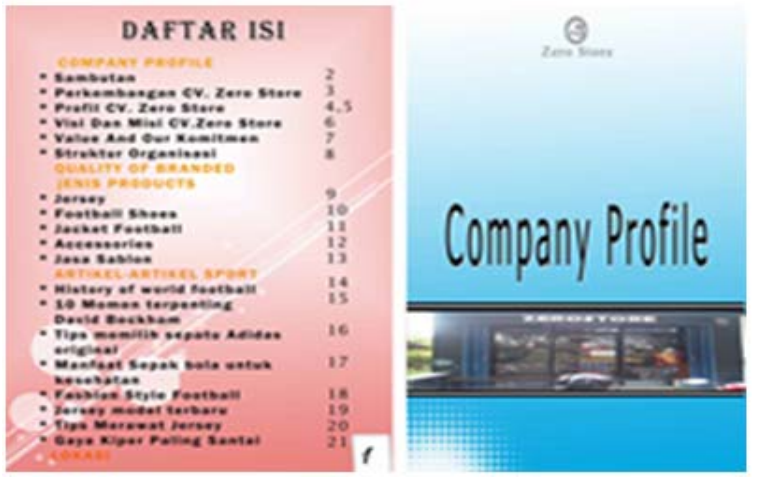

Gambar 8.Final Art Work Sambutan dan Perkembangan Perusahaan serta profil perusahaan

d. Final Art Work Visi Misi, Value our commitment, struktur organisasi dan quality of branded

Pada Final Art Work ini terdapat visi misi dan Value Our commitment. Pada Final Art Work ini juga terdapat struktur organisasi dan quality of branded.
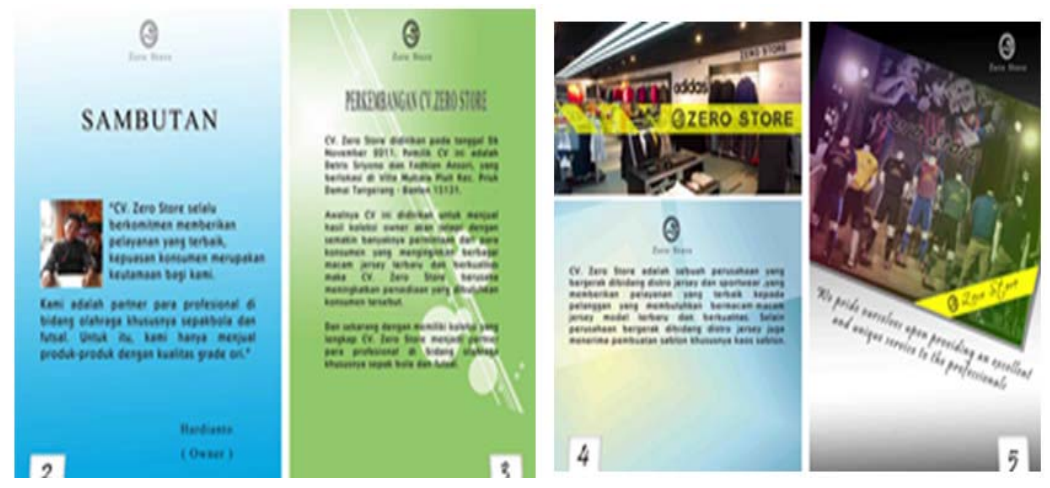

Gambar 9.Final Art Work Visi Misi dan Value Our Komitment

\section{e. Final Art Work Jenis Products dan Jersey}

Desain halaman untuk Jenis Products dan jersey terdapat logo perusahaan dan produk-produk dari cv.zero store dan menggunakan background bewarna oranye dan gradasi putih. Menggunakan huruf pristine. Desain halaman football shoes terdapat poduk football shoes cv.zero store,jacket football dan terdapat logo sedangkan background yang digunakan warna gradasi hitam dan abu abu yang memberikan kesan elegan sport. Menggunakan huruf Matira MT Script Capitals. 

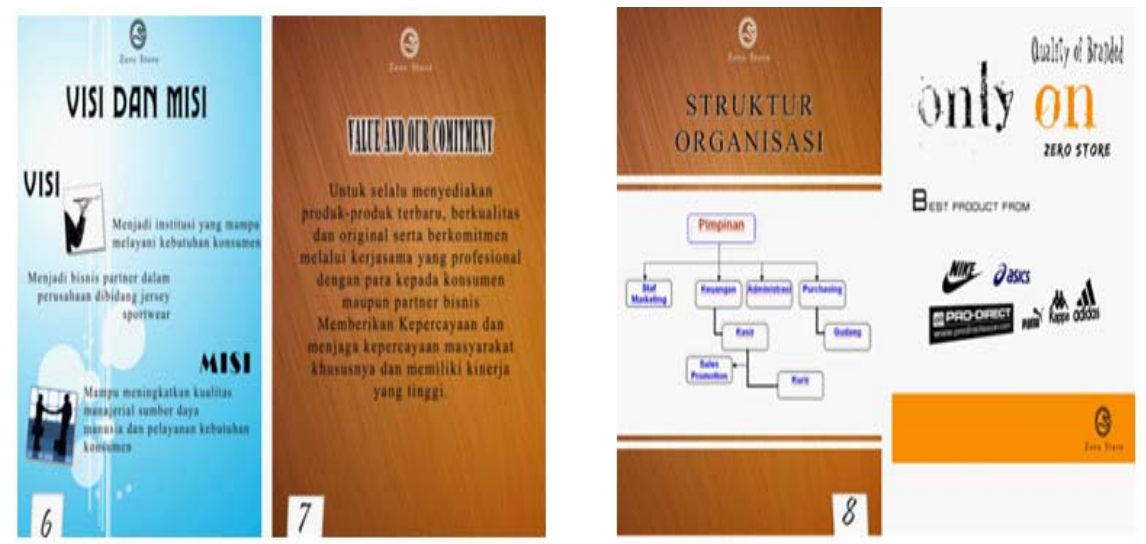

Gambar 10. Final Art Work Jenis Products , Jersey, Footballshoes dan Jacket football

\section{f. Final Art Work Accessories dan Jasa Sablon}

Pada Final Art Work ini juga terdapat jenis accessories dan jasa sablon yang merupakan usaha dari perusahaan.
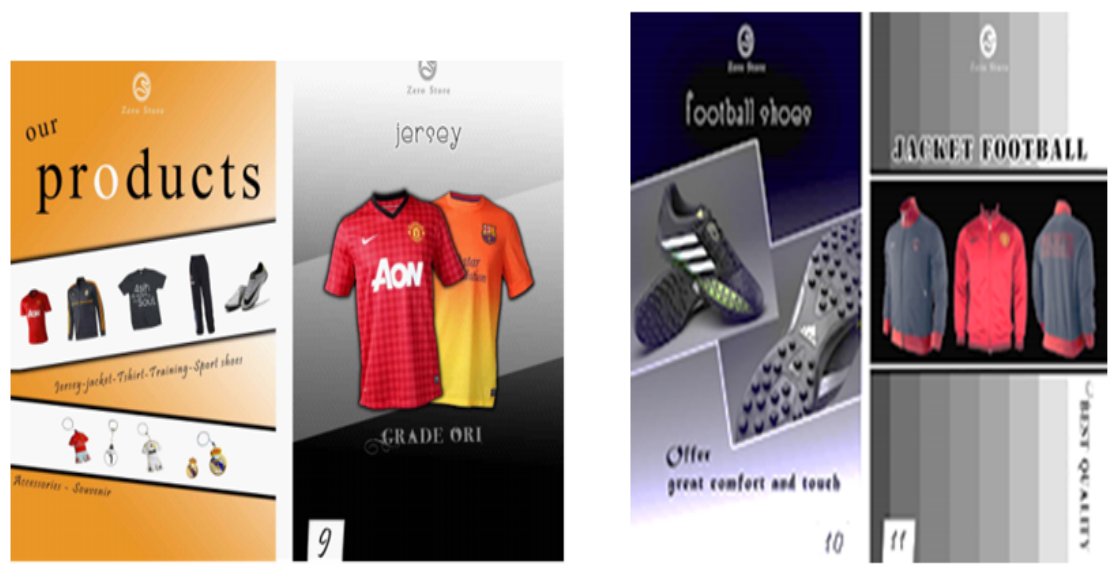

Gambar 11. Final Art Work Accessories dan Jasa Sablon

g. Final Art Work Artikel-Artikel Sport dan History of world

Dalam desain ini terdapat gambar yang bermain bola agar memberi kesan sport background yang digunakan warna putih dan terdapat elemen kotak warna oranye yang memberikan kesan minimalis dan menggunakan huruf Wide L . 


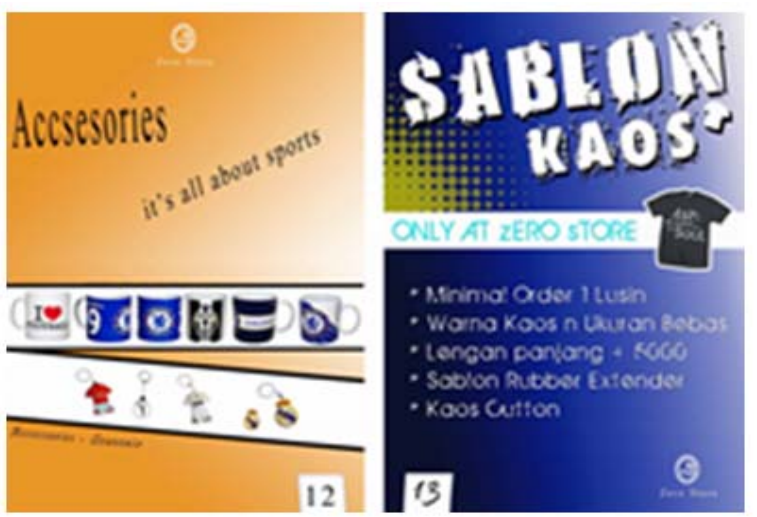

Gambar 12. Final Art Work Artikel- Artikel Sport, History of world

h. Final Art Work tentang, tips memilih sepatu original dan Fashion style football

Pada Final Art Work ini juga memberikan sedikit artikel sport yaitu tentang David Beckham dan tips memilih sepatu original.
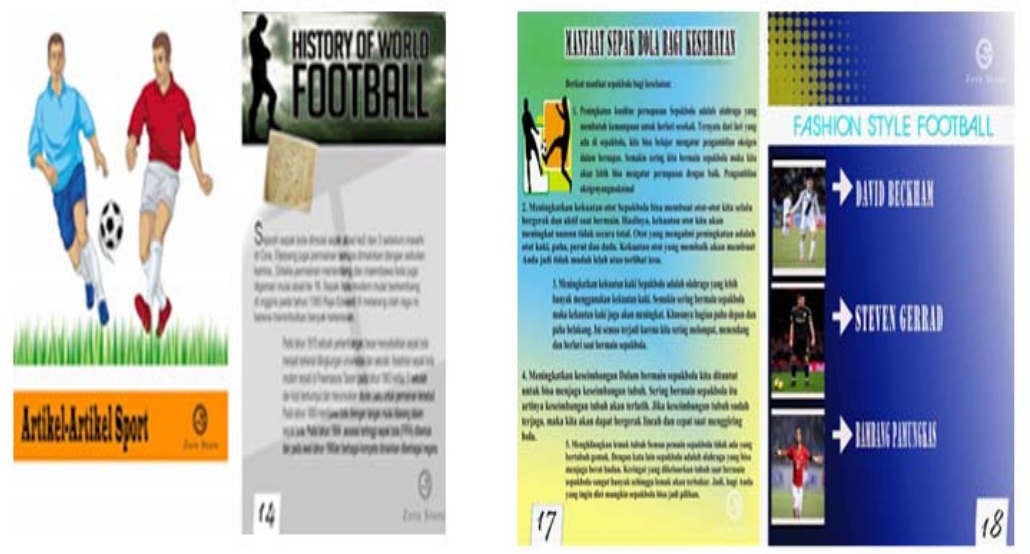

Gambar 13. Final Art Work david beckham, tips memilih sepatu original dan Fashion style football

i. Final Art Work cerita sport dan peta lokasi.

PadaFinal Art Work ini juga memberikan artikel sport yaitu gaya kiper paling santai dan lokasi perusahaan yang memiliki peta perusahaan. 

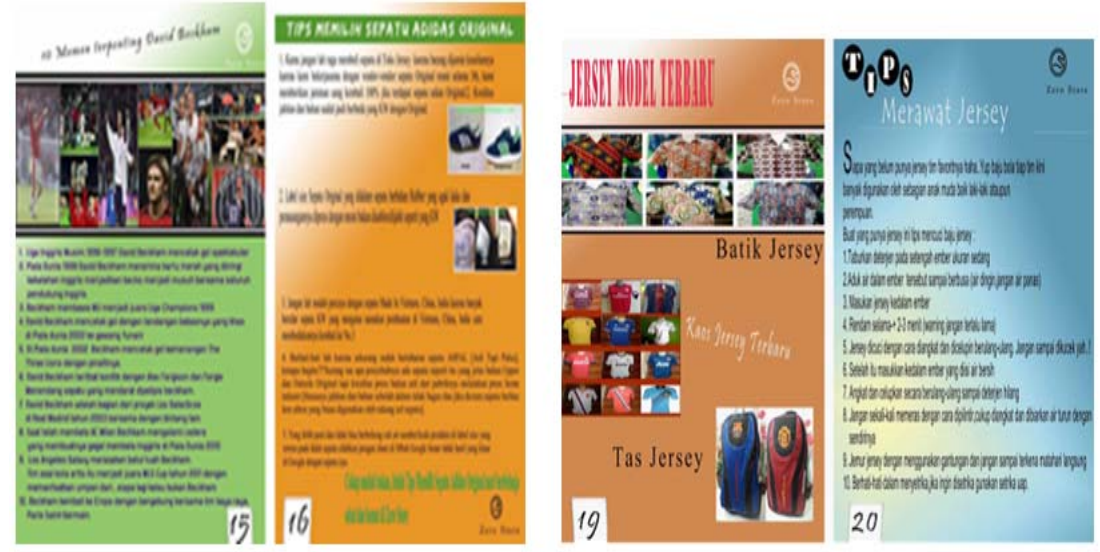

Gambar 14.Final Art Work gaya kiper palin santai dan Lokasi.

\section{KESIMPULAN}

Profil perusahaan yang dikemas dalam bentuk media katalog yang efektif ini agar dapat memberi manfaat bagi perusahaan dan konsumen dan juga katalog yang dibuat denga mudan dibawa dan dalam penyebaran katalog mudah dan isinya menarik serta informasi produk lebih lengkap.

Dengan adanya ptofil perusahaan dalam bentuk katalog yang isinya profil perusahaan dan informasi produk perusahaan diharapkan dapat meningkatkan suatu image atau citra perusahaan untuk menjalin kerja sama dengan relasi perusahaan ,lembaga dan instansi yang terkait lainnya dan dapat dijadikan sebuah aset perusahaan dalam memperkenalkan kapasitas dan kualitas perusahaan kepada para pelaku bisnis yang ingin bekerja sama. Profil perusahaan yang dibuat dengan rancangan desain yang sportif dan casual sesuai dengan image atau citra perusahaan. Dan profil perusahaan yang dibuat dengan desain tempate yang menarik bertujan untuk mempromosikan produk perusahaan an memperkuat perusahaan dalam menjalin relasi atau kerjasama dengan perusahaan terkait dan dapat membangun suatu kepercayaan dari mitra usaha atau pihak-pihak terkait lainnya.

Dengan adanya profil perusahaan yang dikemas dalam bentuk media katalog penulis menyarankan agar perusahaan memberikan profil perusahaan kepada konsumen dan perusahaan yang akan melakukan kerja sama dengan tujuan memeprkenalkan kapasitas dan kuatintas perusahaan serta dapat meningkatkan image atau sitra perusahaan. 


\section{DAFTAR PUSTAKA}

[1] Andri, Muhammad. 2008. Utilization of Information Technology in the Development of iLearning Media. Teknik Elektro, Universitas Gadjah Mada. Yogyakarta.

[2] Handoko, Sapto. 2009. Efektifitas Pemanfaatan Media Audio Visual Sebagai Alternatif Optimalisasi Model Pembelajaran. Universitas Negeri Makasar.

[3] Setiawan,Gunanto. 2010. Analisis Dan Perancangan Aplikasi Mobile Katalog Buku Dengan Teknologi J2ME. Yogyakarta: STMIK AMIKOM. [4] Satrio, Deya, Uji, Putra. 2011.Perancangan Media Katalog Wisata Kota Surabaya Media Informasi Massa. Malang : Universitas Negeri Malang.

[5] Tusfia, Salis. 2010. Pembuatan Katalog Digital Museum Anak Kolong Tangga di Taman Budaya Yogyakarta Dengan Menggunakan Macromedia Flash MX. Yogyakarta: STMIK AMIKOM

[6] Tello, Lucía P. Barroso. 2000. Movies a powerful Resource of Visual Literacy in Journalism Ethics 